\title{
Refusnik scientists: keeping science alive
}

Max Gottesman, from the Laboratory of Molecular Biology at the National Cancer Institute at NIH, was one of ten Western scientists who attended the special four-day Jubilee meeting of the refusnik Sunday Seminar in Moscow earlier this year; the seminar dissolved itself for a 'summer recess' in May following offlcial pressure, and reconvened again last Sunday under Viktor Brailovskii. Below, his views of the refusniks' position

FIVE years ago, the first of the refusnik Sunday Seminars on Collective Phenomena met in a Moscow apartment. Refusniks, unlike dissidents who wish to change Soviet Society, are Jews who wish to leave Russia, usually for Israel. In the case of refusnik scientists, visas to emigrate are often refused on the grounds that the applicant is in possession of "classified information". Not only is their emigration forbidden, but their official scientific life is terminated. They are expelled from their laboratories and denied library privileges; even their telephones are removed. The cut-off is usually very effective: none of Professor Benjamin Levich's colleagues, for example, nor any of the students he had trained over the years, spoke to him after he applied to emigrate.

In an attempt to stay alive scientifically, the refusniks meet together in someone's apartment each Sunday afternoon to discuss science. These meetings have come to attract Western scientists invited to Soviet-sponsored conferences, and they present papers; sometimes establishment Soviet scientists discretely listen to the presentations while remaining in the kitchen. But the special Jubilee meeting held to mark these five years was also accompanied by the constant presence of KGB men stationed outside Dr Mark Azbel's apartment, where the seminar was held.

They followed the Western scientists wherever we went. Usually consisting of four men in a taxi, they made no attempt to disguise the fact that we were being followed; they were there clearly to intimidate us. One afternoon, a truckload of soldiers unloaded below Azbel's window and lounged around several hours before leaving. A parked van, left with the motor running and no driver, contained the monitoring devices used by the KGB to follow the conversations in the apartment. Between the sessions, however, matters of a non-scientific nature were discussed, and from these talks and exchanges of written notes I obtained a picture of the present status of the refusnik scientists.

How the refusniks manage to survive varies from case to case. Some had accumulated savings before applying for an exit visa. Of course a long five- or six-year period of refusal cannot be prepared for in this way. During refusal, they find occasional work, sometimes as manual labourers and sometimes as tutors. Unfortunately tutoring positions tend to be transitory; a discrete call from the KGB to a family employing a refusnik tutor usually has the expected effect.

It is clear that the scientists who have entered into refusal have a common motivation: to escape the severe and worsening anti-semitism in Russia. The Russians wish to exclude Jews from the sciences and other professions. At the present time, it is difficult or impossible for a Jewish student to enter a first-rate university. An example: the medical school in Odessa, a city with a large Jewish population, has not a single Jewish student. Thus many Jews are driven to emigrate to assure their children equal educational and employment opportunities. Current Soviet antisemitism comes after a long period of relative tolerance. A generation of Jews has been assimilated, and the refusniks find themselves without an inheritance of Jewish culture.
They are anxious to regain their heritage-and to learn Hebrew-in the face of severe pressure from the authorities. It is no accident that the two refusniks currently in prison, Joseph Begu and Anatolii Shcharanskii, were the most active in disseminating Jewish culture. And yet, in spite of the threats, there were several refusniks at the seminar I attended wearing Israeli pins in their lapels.

Why don't the Soviets just let the refusniks emigrate? In fact, some are permitted to go; but the rate is slow, and getting slower. The Soviets fear that an easy emigration policy will result in Jews as well as other national groups demanding, en masse, to emigrate, thus threatening the stability of the State. Also, the Jewish scientists have a special problem. The justification of the Soviet system is 'scientific'; Markist-Leninist analysis of history and economics has proved, in a manner as certain as $E=m c^{2}$, that Soviet society is structured correctly. For a scientist to desire to emigrate is unthinkable. It should be mentioned that the only valid reason for leaving Russia is to rejoin one's family abroad.

What can be done? In view of the fact that the Soviets greatly value scientific contacts with the West, certain courses of action are feasible. In particular, international meetings and exchanges can be used to help the refusniks. Refusnik scientists wish to participate in these open meetings and could be invited. If such participation is denied by the authorities, Western organisers should consider either the possibility of moving the meeting from Soviet territory, or of limiting Soviet participation in meetings held in the West. In the case of the International Genetics Conference, to be held in Moscow in the summer of 1978, a precedent has been set. A prior conference was moved from the United States to Canada in the 1950s when the US State Department refused to issue visas to certain foreign scientists.

Publicity is essential to keep the refusniks from simply disappearing. Official Soviet visitors should be reminded that the treatment of refusnik scientists threatens SovietWestern exchange programmes. Since visitors are invariably debriefed by the $\mathrm{KGB}$ on their return, this is an effective means of reaching the Soviet authorities. It should also be remembered that the critical decision as to whether a refusnik's work is 'classified' is made by his departmental superiors, or the chairman of his department. These are often the very scientists who are sent to Western conferences and exchange programmes.

Finally, it should be stressed that scientists visiting Russia are warmly welcomed at the Sunday Seminar, and are doing a great service to the refusniks by attending. For addresses and other information contact the Committee for Concerned Scientists, 9 East 40 Street, New York, New York, 10016.

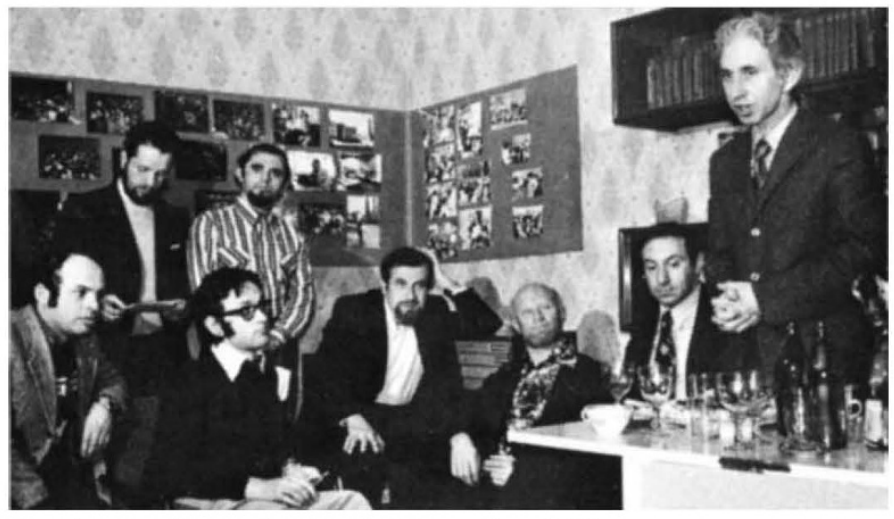

Sunday Seminar scientists in November 1976 